\title{
Strategi ruang terbuka hijau pemakaman di Kota Pekanbaru
}

\author{
Muhammad Fahrul ${ }^{1}$, Yusni Ikhwan Siregar ${ }^{2}$, Sukendi ${ }^{2}$ \\ ${ }^{1}$ Environment Officer di First Resources Group \\ ${ }^{2}$ Pascasarjana Ilmu Lingkungan Program Pascasarjana Universitas Riau \\ *Correspondent email : Muhammad.fahrul@gmail.com
}

\begin{abstract}
One alternative to overcome the issue of Pekanbaru City Open Space quantity that does not meet the requirements is to reorganize the function and optimization of existing Open Space. A potential open space that has been neglected is cemetery. Cemetery are often ignored because of images related to death, whereas in addition to social functions, there are also ecological and economic functions. One form of cemetery is a public cemetery (TPU) managed by the Pekanbaru City government. Given its potential, a funeral green space strategy is needed. Strategic formulation using SWOT and priority setting using AHP. Inputs needed in the preparation of this strategy are the existing conditions and their compliance with funeral green space guidelines, people's perceptions and preferences.
\end{abstract}

Keywords: Open Space; Cemetery; SWOT; AHP; Perception; Preferences

Kota Pekanbaru memiliki luas sebesar 63.226 Ha, idealnya menurut Undang Undang no 26 tahun 2007 wajib menyediakan RTH minimal seluas $18.967,8$ Ha dengan pembagian RTH publik seluas 12.645,2 Ha dan RTH privat seluas 6.322,6 Ha. Parlindungan (2018) menyimpulkan luas RTH publik kota Pekanbaru pada Tahun 2018 adalah sebesar 419,72 Ha. Artinya terdapat kekurangan RTH publik sebanyak 12.225,5 Ha atau hanya $3.32 \%$ dari kondisi yang ideal. Hambatan RTH kota Pekanbaru disebabkan lemahnya kemampuan pemerintah untuk menata lahan yang tersedia dan membuka lahan RTH baru, belum efektifnya perencanaan dan penerapan program RTH, rendahnya peran serta swasta dan kesadaran masyarakat mengenai RTH (Ardiansah, 2019).

Proses perencanaan pembangunan kota yang berwawasan lingkungan dengan konsep kota ekologi, salah satu upaya yang dapat dilakukan adalah menjaga dan mengembalikan RTH ke dalam lingkungan perkotaan dengan berbentuk sistem, sehingga dapat berperan optimal dari sisi ekologi, sosial dan ekonomi. Alternatif yang bisa dilakukan adalah dengan meningkatkan kualitas RTH kota melalui penataan ulang fungsi dan optimalisasi RTH eksisting.

Tempat pemakaman sebagai merupakan salah satu unsur RTH publik tertentu memiliki fungsi sosial sebagai tempat memakamkan jenazah dan ziarah makam, juga berfungsi ekologis, memiliki asosiasi yang kuat dengan kematian dan cenderung menjadi hal yang ditakutkan oleh masyarakat, menimbulkan kesan mistis sehingga keberadaannya sering diabaikan. Pemakaman terdiri dari beberapa jenis dan salah satunya adalah Tempat Pemakaman Umum (TPU) yaitu pemakaman yang dikelola oleh pemerintah diperuntukkan untuk semua lapisan masyarakat kota. Di kota Pekanbaru, terdapat 6 TPU yang tersebar di 6 Kecamatan dengan total luas lahan sebesar 31,82 Ha. Sehingga jika dikelola dengan baik, maka TPU tersebut dapat berkontribusi terhadap penyediaan RTH di Kota Pekanbaru. Perda Kota Pekanbaru no 3 tahun 2012 dan Permenpu no 5 tahun 2008 adalah pedoman dalam penataan RTH pemakaman.

\section{METODE PENELITIAN}

Penelitian mengambil objek di TPU Tampan yang dianggap mewakili TPU lain yang berada di Kota Pekanbaru, mengambil waktu di bulan Mei 2020 yang bertepatan dengan bulan Ramadhan 1441 Hijriah, dimana aktivitas masyarakat dalam berziarah kubur meningkat. Responden untuk persepsi dan preferensi dipilih dengan purposive sampling, yang ditemukan di areal TPU Tampan sebanyak 349 orang. Responden untuk SWOT dan AHP adalah stakeholder Kota Pekanbaru yang dianggap ahli terkait penelitian yaitu Dinas Perkim, Bappeda dan Dinas PUPR, jumlah responden 6 orang. Observasi lapangan dilakukan untuk menilai kesesuaian RTH pemakaman TPU Tampan dinilai kesesuaiannya dengan pedoman perda Kota Pekanbaru no 3 tahun 2012 dan permenpu no 5 tahun 2008. Persepsi dan preferensi responden menggunakan kuesioner dan menggunakan metode chi square untuk mengetahui hubungan karakteristik responden dengan preferensi responden, pengolahan dengan software SPSS versi 20. Perumusan strategi menggunakan metode SWOT untuk merumuskan strategi dan metode AHP untuk menentukan prioritas alternatif strategi menggunakan software Expert Choice versi 11. 


\section{HASIL DAN PEMBAHASAN}

Kesesuaian TPU Tampan dengan pedoman RTH pemakaman yang diacu adalah Perda Kota Pekanbaru no 3 tahun 2012 dan Permenpu no 5 tahun 2018. Aspek yang dinilai adalah ukuran petak makam, jarak antar makam, blok makam, jalan, vegetasi yang diperoleh dari observasi lapangan.

Tabel 1. Kesesuaian TPU Tampan Dengan Pedoman

\begin{tabular}{|c|c|c|c|}
\hline Parameter & $\begin{array}{l}\text { Perda no } 3 \\
\text { tahun } 2012\end{array}$ & Permenpu no 5 tahun 2008 & TPU Tampan \\
\hline Ukuran makam & $\begin{array}{llll}\text { Maks } & 2,5 & \mathrm{~m} & \mathrm{x} \\
1,5 \mathrm{~m} & & & \end{array}$ & $1 \mathrm{~m} \times 2 \mathrm{~m}$ & $\begin{array}{l}\text { Usia } 5 \text { tahun kebawah : variasi } \\
0,5 \mathrm{~m}-0,8 \mathrm{~m} \times 0,8 \mathrm{~m}-1 \mathrm{~m} \\
\text { Usia } 5 \text { tahun ke atas : bervariasi } \\
0,8 \mathrm{~m}-1 \mathrm{~m} \times 1,8 \mathrm{~m}-2 \mathrm{~m}\end{array}$ \\
\hline $\begin{array}{l}\text { Jarak antar } \\
\text { makam }\end{array}$ & $0,4 \mathrm{~m}$ & Min $0,5 \mathrm{~m}$ & Bervariasi antara $0,3 \mathrm{~m}-0,5 \mathrm{~m}$ \\
\hline Pengerasan & Dilarang & Dilarang & $\begin{array}{l}\text { Tidak ada pengerasan kecuali } \\
\text { nisan }\end{array}$ \\
\hline $\begin{array}{l}\text { Pembagian blok } \\
\text { makam }\end{array}$ & $\begin{array}{l}\text { Blok makam } \\
\text { beda agama } \\
\text { dipisahkan min } \\
3 \mathrm{~m}\end{array}$ & $\begin{array}{l}\text { Dibagi dalam blok sesuai kondisi } \\
\text { makam }\end{array}$ & $\begin{array}{l}\text { Blok makam dibagi per } 350 \mathrm{~m}^{2} \\
\text { Blok makam muslim dan non } \\
\text { muslim terpisah lebih dari } 3 \mathrm{~m}\end{array}$ \\
\hline Batas antar blok & $\begin{array}{l}\text { Jalan minimal } \\
\text { lebar } 2,5 \mathrm{~m}\end{array}$ & $\begin{array}{l}\text { Pedestrian lebar } 1,5-2 \mathrm{~m} \\
\mathrm{~cm} \text { dengan deretan pohon pelindung } \\
\text { disalah satu sisinya }\end{array}$ & $\begin{array}{l}\text { Pedestrian dengan lebar } \\
\text { bervariasi antara } 1 \mathrm{~m}-2 \mathrm{~m} \text {, } \\
\text { tidak semua ada pohon } \\
\text { pelindung }\end{array}$ \\
\hline $\begin{array}{l}\text { Batas terluar } \\
\text { pemakaman }\end{array}$ & Tidak mengatur & $\begin{array}{l}\text { pagar tanaman atau kombinasi antara } \\
\text { pagar buatan dengan pagar tanaman, } \\
\text { atau dengan pohon pelindung }\end{array}$ & $\begin{array}{l}\text { Pagar tembok tanpa kombinasi } \\
\text { pagar tanaman maupun pohon } \\
\text { pelindung }\end{array}$ \\
\hline $\begin{array}{l}\text { Ruang hijau } \\
\text { pemakaman } \\
\text { termasuk } \\
\text { pemakaman }\end{array}$ & Tidak mengatur & $\begin{array}{l}\text { tanpa perkerasan minimal } 70 \% \text { dari } \\
\text { total area pemakaman, tingkat liputan } \\
\text { vegetasi } 80 \% \text { dari luas ruang hijaunya }\end{array}$ & $\begin{array}{l}\text { Area perkerasan }<20 \% \text { berupa } \\
\text { tempat berkumpul, kantor } \\
\text { pengelola dan jalan beton dan } \\
\text { paving block. Tingkat liputan } \\
\text { vegetasi sekitar } 80 \% \text { yang } \\
\text { didominasi oleh rumput dan } \\
\text { perdu liar }\end{array}$ \\
\hline Vegetasi & $\begin{array}{l}\text { Tidak } \\
\text { Mengatur }\end{array}$ & $\begin{array}{l}\text { Bougenvil, Kamboja Putih, Puring, } \\
\text { Lili Pita, Tanjung, Dadap, Kembang } \\
\text { Merak, Jamblang, Salam. }\end{array}$ & $\begin{array}{l}\text { Vegetasi berupa rumput dan } \\
\text { perdu liar, pohon Matoa, } \\
\text { Mahoni, Pulai, Kelapa Sawit, } \\
\text { Ketapang dan tanaman ubi }\end{array}$ \\
\hline
\end{tabular}

Dari hasil kuesioner yang dibagikan, persepsi responden terhadap kondisi keindahan, kebersihan, kenyamanan, keamanan dan pelayanan pengelola TPU Tampan secara umum adalah buruk. Sedangkan untuk persepsi RTH secara umum, mayoritas responden sudah mengetahui dan menyadari pentingnya RTH, dan menilai kondisi RTH di Kota Pekanbaru di level cukup. Untuk persepsi RTH pemakaman, mayoritas responden sebelumnya tidak mengetahui tentang RTH pemakaman, tetapi setelah tahu, mayoritas responden menganggap bahwa RTH pemakaman itu penting untuk lingkungan dan bersedia untuk berperan dalam perencanaan dan pengelolaan RTH pemakaman. Preferensi masyarakat terhadap RTH pemakaman TPU Tampan adalah mengutamakan manfaat RTH pemakaman terhadap lingkungan hidup yang mengutamakan kenyamanan pilihan softscape berupa vegetasi peneduh. Karakterisitik responden berupa jenis kelamin, pendidikan, pekerjaan dan pendapatan berpengaruh terhadap pilihan pada aspek manfaat, unsur, elemen landscape, vegetasi dan aspek makam.

Perumusan strategi RTH pemakaman TPU Tampan melibatkan unsur lingkungan, masyarakat Dalam perumusan strategi RTH Pemakaman di Kota Pekanbaru dengan objek TPU Tampan menggunakan 2 metode yaitu metode SWOT dan AHP. Pertama adalah metode SWOT, dengan tujuan untuk menemukan aspek-aspek penting dari kekuatan, kelemahan, peluang, dan ancaman di dalam RTH Pemakaman TPU Tampan. Perangkat yang digunakan dalam penyusunan strategi SWOT adalah perangkat analisis Internal Faktor Analisis Strategi (IFAS), Eksternal Faktor Analisis Strategi (EFAS) dan matrik SWOT. Metode kedua adalah metode AHP, yang digunakan untuk menentukan prioritas strategi yang dihasilkan dari metode SWOT. Hasil analisis AHP inilah yang akan menjadi rekomendasi alternatif strategi kebijakan dalam pengambilan keputusan untuk mencapai tujuan yang diharapkan. 
Berdasarkan kajian literatur, hasil observasi lapangan, hasil kuesioner persepsi dan preferensi masyarakat dan survey pendahuluan di dinas terkait di Kota Pekanbaru, maka diperoleh elemen faktorfaktor internal dan eksternal yang dinilai bobot dan prioritasnya oleh responden dengan hasil IFAS EFAS dan matrik SWOT sebagai berikut :

Tabel 2. Faktor Internal

\begin{tabular}{clcc}
\hline \multirow{2}{*}{ No } & \multicolumn{1}{c}{ Faktor-faktor } & \multicolumn{2}{c}{ Penilaian Kondisi } \\
& & Rata-rata & Ket \\
\hline 1 & Lokasi TPU Tampan & 4,17 & S1 \\
2 & Kondisi topografi & 1,67 & W1 \\
3 & Potensi SDA & 2,00 & W2 \\
4 & Kualitas dan kuantitas SDM Pengelola & 4,00 & S2 \\
5 & Sumber PAD & 4,17 & S3 \\
6 & Regulasi pemakaman & 3,83 & S4 \\
7 & Manual pengelolaan pemakaman & 4,17 & S5 \\
8 & Pendanaan & 1,83 & W3 \\
9 & Ketersediaan sarana & 1,50 & W4 \\
10 & Pengelolaan dan pengaturan makam & 1,50 & W5 \\
11 & Sosialisasi peraturan dan informasi makam & 1,83 & W6 \\
12 & TPU Tampan terbuka untuk semua agama & 4,33 & S6 \\
13 & RTRW Kota Pekanbaru & 2,33 & W7 \\
14 & RPJPD dan RPJMD Kota Pekanbaru & 4,17 & S7 \\
15 & Renstra Dinas Perkim Kota Pekanbaru & 3,67 & S8 \\
& & 3,01 & \\
\hline
\end{tabular}

Tabel 3. Faktor Eksternal

\begin{tabular}{llcc}
\hline \multirow{2}{*}{ No } & \multicolumn{1}{c}{ Faktor-faktor } & \multicolumn{2}{c}{ Penilaian Kondisi } \\
& & Rata-rata & Ket \\
\hline 1 & Peraturan RTH dan makam & 3,83 & O1 \\
2 & RTRW Provinsi Riau & 4,17 & O2 \\
3 & Pemakaman dengan konsep RTH yang berhasil & 4,83 & O3 \\
4 & Partisipasi dari pihak luar & 4,33 & O4 \\
5 & Persepsi dan preferensi masyarakat & 4,33 & O5 \\
6 & Okupasi lahan & 2,00 & T1 \\
7 & Vandalisme & 2,00 & T2 \\
8 & Sempadan lahan & 2,33 & T3 \\
9 & Peluang ekonomi masyarakat & 4,33 & O6 \\
& & 3,52 & \\
\hline
\end{tabular}


Tabel 4. IFAS

\begin{tabular}{|c|c|c|c|c|c|}
\hline \multirow{2}{*}{ SWOT } & \multirow{2}{*}{ No } & \multicolumn{2}{|c|}{ Bobot Penilaian } & \multirow{2}{*}{$\begin{array}{l}\text { Rating } \\
\text { Prioritas }\end{array}$} & \multirow{2}{*}{ Bobot $\mathrm{x}$ Rating } \\
\hline & & Rata-rata & Penyesuaian & & \\
\hline \multirow{8}{*}{$\begin{array}{l}5 \\
5 \\
5 \\
5 \\
5\end{array}$} & $\mathrm{~S} 1$ & 4.17 & 0.13 & 2.33 & 0.30 \\
\hline & $\mathrm{S} 2$ & 4.00 & 0.12 & 3.00 & 0.37 \\
\hline & $\mathrm{S} 3$ & 4.17 & 0.13 & 2.50 & 0.32 \\
\hline & S4 & 3.83 & 0.12 & 3.50 & 0.41 \\
\hline & S5 & 4.17 & 0.13 & 3.83 & 0.49 \\
\hline & S6 & 4.33 & 0.13 & 3.67 & 0.49 \\
\hline & S7 & 4.33 & 0.13 & 3.33 & 0.44 \\
\hline & S8 & 3.67 & 0.11 & 3.00 & 0.34 \\
\hline Total & & 32.67 & 1.00 & & 3.15 \\
\hline \multirow{7}{*}{ 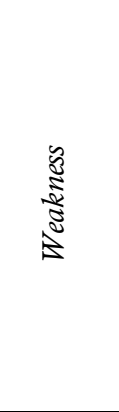 } & W1 & 1.67 & 0.13 & 3.50 & 0.45 \\
\hline & W2 & 2.00 & 0.15 & 3.33 & 0.51 \\
\hline & W3 & 2.00 & 0.15 & 3.33 & 0.51 \\
\hline & W4 & 1.50 & 0.12 & 3.50 & 0.40 \\
\hline & W5 & 1.67 & 0.13 & 3.83 & 0.49 \\
\hline & W6 & 1.83 & 0.14 & 3.50 & 0.49 \\
\hline & W7 & 2.33 & 0.18 & 3.67 & 0.66 \\
\hline Total & & 13.00 & 1.00 & & 3.52 \\
\hline
\end{tabular}

Tabel 5. EFAS

\begin{tabular}{|c|c|c|c|c|c|}
\hline \multirow{2}{*}{ SWOT } & \multirow{2}{*}{ No } & \multicolumn{2}{|c|}{ Bobot Penilaian } & \multirow{2}{*}{$\begin{array}{l}\text { Rating } \\
\text { Prioritas }\end{array}$} & \multirow{2}{*}{ Bobot x Rating } \\
\hline & & Rata-rata & Penyesuaian & & \\
\hline \multirow{6}{*}{ 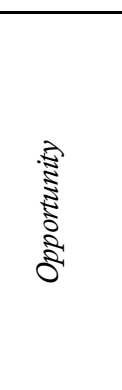 } & 01 & 3.83 & 0.15 & 3.17 & 0.47 \\
\hline & $\mathrm{O} 2$ & 4.17 & 0.16 & 3.33 & 0.54 \\
\hline & $\mathrm{O} 3$ & 4.83 & 0.19 & 3.83 & 0.72 \\
\hline & $\mathrm{O} 4$ & 4.33 & 0.17 & 3.50 & 0.59 \\
\hline & O5 & 4.33 & 0.17 & 3.83 & 0.64 \\
\hline & O6 & 4.33 & 0.17 & 3.67 & 0.62 \\
\hline Total & & 25.82 & 1.00 & & 3.57 \\
\hline \multirow{3}{*}{ है } & $\mathrm{T} 1$ & 2.00 & 0.32 & 3.00 & 0.95 \\
\hline & $\mathrm{T} 2$ & 2.00 & 0.32 & 3.50 & 1.11 \\
\hline & $\mathrm{T} 3$ & 2.33 & 0.37 & 3.33 & 1.23 \\
\hline Total & & 6.33 & 1.00 & & 3.28 \\
\hline
\end{tabular}


Tabel 6. Matrik SWOT

\begin{tabular}{|c|c|c|}
\hline & $\begin{array}{c}\text { Kekuatan (strength) } \\
\text { Bobot : } 3.15 \\
\text { S1, S2, S3, S4, S5, S6, S7, } \\
\text { S8 }\end{array}$ & $\begin{array}{c}\text { Kelemahan (weakness) } \\
\text { Bobot : } 3.52 \\
\text { W1, W2, W3, W4, W5, W6, W7 }\end{array}$ \\
\hline $\begin{array}{c}\text { Peluang (Opportunity) } \\
\text { Bobot : } 3.57 \\
\mathrm{O} 1, \mathrm{O} 2, \mathrm{O} 3, \mathrm{O} 4, \mathrm{O} 5, \mathrm{O} 6\end{array}$ & $\begin{array}{c}\text { SO (Bobot : 6.72) } \\
\text { SO1, SO2, SO3, SO } 4\end{array}$ & $\begin{array}{c}\text { WO (Bobot : 7.09) } \\
\text { WO1, WO2, WO3, WO4 }\end{array}$ \\
\hline $\begin{array}{c}\text { Ancaman (threat) } \\
\text { Bobot }: 3.28 \\
\mathrm{~T} 1, \mathrm{~T} 2, \mathrm{~T} 3 \\
\end{array}$ & $\begin{array}{c}\text { ST (Bobot : 6.43) } \\
\text { ST1, ST2 }\end{array}$ & $\begin{array}{l}\text { WT (Bobot : 6.8) } \\
\text { WT 1, WT 2, WT3 }\end{array}$ \\
\hline
\end{tabular}

Pembobotan terbesar 7.09 berada di kuadran WO (Weakness - Oppurtunity) sehingga alternatif strategi yang terpilih adalah menanggulangi kelemahan dengan mengoptimalkan kesempatan dengan rincian sebagai berikut :

Tabel 7. Strategi WO

\begin{tabular}{|l|l|}
\hline \multicolumn{1}{|c|}{ Weakness } & \multicolumn{1}{c|}{ Oppurtunity } \\
Kondisi Topografi (W1) & Peraturan RTH dan makam (O1) \\
Potensi SDA (W2) & RTRW Provinsi Riau (O2) \\
Pendanaan (W3) & Pemakaman dengan konsep RTH (O3) \\
Ketersediaan Sarana (W4) & Partisipasi dari luar (O4) \\
Pengelolaan dan pengaturan makam (W5) & Persepsi dan preferensi masyarakat (O5) \\
Sosialisasi peraturan dan informasi makam (W6) & Peluang ekonomi masyarakat (O6) \\
\hline \multicolumn{2}{|c|}{ STRT Kota Pekanbaru (W7) } \\
- pemantapan posisi RTH pemakaman pada RTRW Kota Pekanbaru \\
- pengelolaan makam mengacu ke regulasi dan pemakaman dengan konsep RTH yang sudah berhasil \\
- menjaring partisipasi dari luar \\
- sosialisasi RTH pemakaman ke masy arakat.
\end{tabular}

Hasil alternatif strategi dari SWOT lalu dilanjutkan dengan metode AHP untuk penyusunan prioritas alternatif strategi. Hirarki yang digunakan dalam AHP adalah :

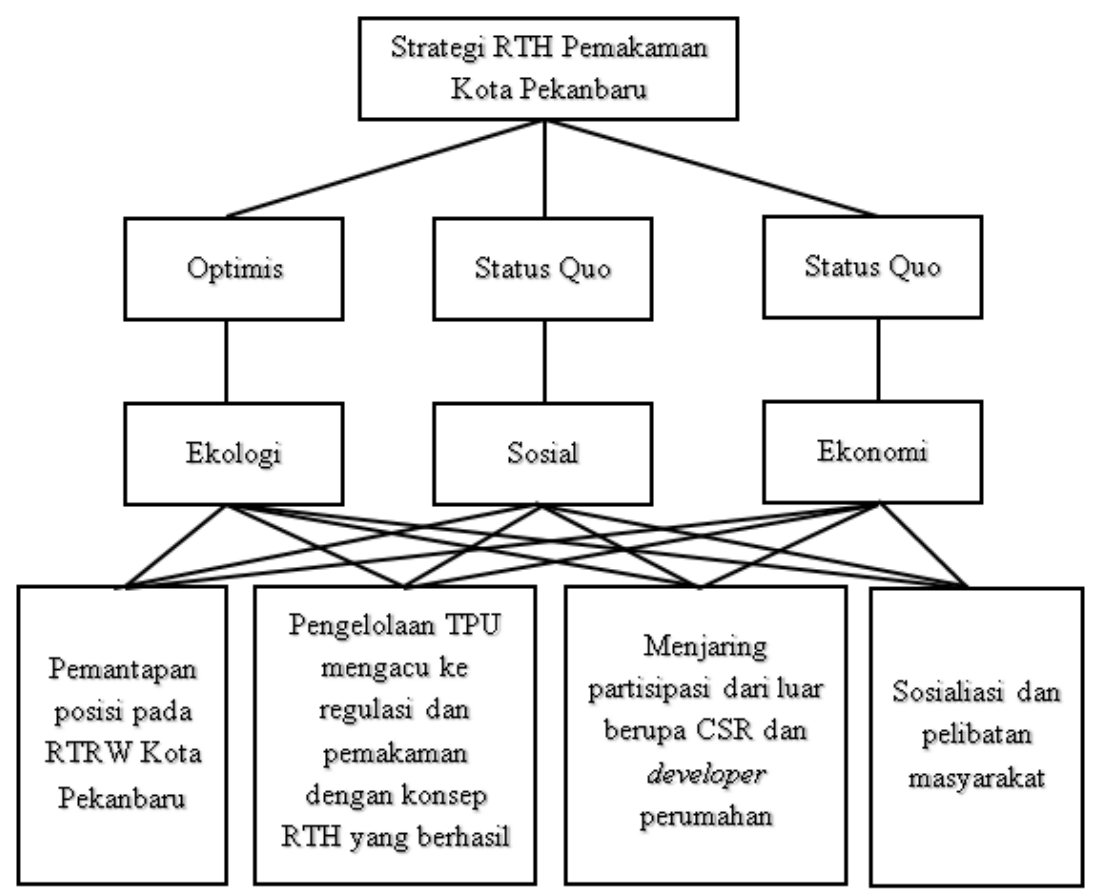

Gambar 1. Hirarki AHP 


\section{ZONA}

Jurnal Lingkungan

Volume 4, No 1, April 2020, p. 33-39

ISSN : 2502-6496 (Print)

http://zona.pelantarpress.co.id

Level 1 adalah skenario, yang terbagi menjadi 3 kemungkinan skenario yang mungkin terjadi, yaitu :

1. Skenario Optimis, merupakan skenario masa depan dimana kondisi internal dan eksternal sangat mendukung terhadap RTH pemakaman Kota Pekanbaru, atau kondisi masa depan lebih baik dari kondisi pada masa sekarang sehingga mendukung tercapainya sasaran yang diharapkan.

2. Skenario status quo, merupakan skenario masa depan dimana kondisi internal dan eksternal tetap sama dengan kondisi saat sekarang atau hampir tidak ada perubahan

3. Skenario pesimis, merupakan skenario masa depan dimana kondisi internal dan eksternal lebih buruk dibandingkan kondisi pada saat ini dan mengancam terhadap tercapainya sasaran.

Level 2 adalah sasaran, yang terbagi menjadi 3 sasaran yang hendak dicapai, yaitu:

1. Sasaran terhadap ekologi, adalah suatu sasaran yang bermaksud untuk menambah peran terhadap kualitas lingkungan yang merupakan faktor yang dinilai buruk oleh responden.

2. Sasaran terhadap social, adalah suatu sasaran yang bermaksud mengoptimalkan fungsi TPU dan RTH pemakaman dalam menunjang aktivitas sosial masyarakat.

3. Sasaran terhadap ekonomi, adalah sasaran untuk mengakomodir kebutuhan dan keinginan masyarakat terhadap peluang ekonomi yang ditimbulkan oleh keberadaaan TPU, dengan mengoptimalkan potensipotensi SDA yang ada pada area TPU

Level 3 adalah Alternatif 4 strategi RTH pemakaman Kota Pekanbaru yang diperoleh melalui analisis SWOT, yaitu:

1. Memantapkan posisi RTH pemakaman TPU Tampan pada RTRW Kota Pekanbaru dengan mengacu pada RTRW Provinsi Riau dan mendorong pengesahan RTRW Kota Pekanbaru.

2. Mengarahkan pengelolaan TPU Tampan, khususnya untuk meminimalkan resiko longsor, memaksimalkan pemanfaatan potensi SDA dan mengoptimalkan pengaturan petak makam dengan mengacu pada konsep pemakaman dalam bentuk RTH yang berhasil dan regulasi-regulasi yang ada.

3. Merumuskan dasar dan perangkat hukum beserta prosedur untuk menjaring partisipasi dari luar, seperti CSR dari perusahaan, terutama developer perumahan untuk membantu pengelolaan makam dan juga dari kegiatan ekonomi yang berlangsung di areal makam untuk membantu pendanaan TPU Tampan.

4. Pelibatan partisipasi masyarakat potensinya besar, karena persepsi masyarakat yang positif terhadap fungsi dan keberadaan dengan mensosialisasikan regulasi dan prosedur yang berlaku pada TPU Tampan dan memenuhi kebutuhan masyarakat terhadap RTH pemakaman TPU Tampan.

Dari hirarki tersebut lalu dituangkan ke dalam bentuk kuesioner untuk dilakukan penilaian oleh responden dan dilakukan pengolahan dengan software Expert Choice, hasilnya sebagai berikut:

Tabel 8. Hasil AHP

\begin{tabular}{|c|c|c|c|c|c|c|}
\hline \multirow{2}{*}{ Skenario } & \multirow{2}{*}{ Sasaran } & \multicolumn{4}{|c|}{ Alternatif strategi } & \multirow{2}{*}{$\begin{array}{l}\text { Grand } \\
\text { Total }\end{array}$} \\
\hline & & RTRW & Pengelolaan & Partisipasi & Sosialisasi & \\
\hline \multirow{3}{*}{$\begin{array}{l}\text { Optimis } \\
\text { (L: .102) }\end{array}$} & Ekologi (L: .319) & 0.008 & 0.010 & 0.010 & 0.005 & 0.033 \\
\hline & Ekonomi (L: .107) & 0.003 & 0.003 & 0.003 & 0.002 & 0.011 \\
\hline & Sosial (L: .574) & 0.017 & 0.014 & 0.019 & 0.008 & 0.058 \\
\hline \multicolumn{2}{|c|}{ Optimis (L: .102) Total } & 0.028 & 0.027 & 0.032 & 0.015 & 0.102 \\
\hline \multirow{3}{*}{$\begin{array}{l}\text { Status Quo } \\
\text { (L: .594) }\end{array}$} & Ekologi (L: .161) & 0.025 & 0.027 & 0.032 & 0.011 & 0.095 \\
\hline & Ekonomi (L: .231) & 0.033 & 0.032 & 0.051 & 0.022 & 0.138 \\
\hline & Sosial (L: .608) & 0.090 & 0.054 & 0.146 & 0.071 & 0.361 \\
\hline \multicolumn{2}{|c|}{ Status Quo (L: .594) Total } & 0.148 & 0.113 & 0.229 & 0.104 & 0.594 \\
\hline \multirow{3}{*}{$\begin{array}{l}\text { Pesimis } \\
\text { (L: .304) }\end{array}$} & Ekologi (L: .151) & 0.010 & 0.013 & 0.017 & 0.005 & 0.045 \\
\hline & Ekonomi (L: .159) & 0.011 & 0.009 & 0.021 & 0.007 & 0.048 \\
\hline & Sosial (L: .690) & 0.049 & 0.058 & 0.075 & 0.028 & 0.210 \\
\hline \multicolumn{2}{|c|}{ Pesimis (L: .304) Total } & 0.070 & 0.080 & 0.113 & 0.040 & 0.303 \\
\hline \multicolumn{2}{|c|}{ Grand Total } & 0.246 & 0.220 & 0.374 & 0.159 & 0.999 \\
\hline
\end{tabular}




\section{ZONA}

Jurnal Lingkungan

Volume 4, No 1, April 2020, p. 33-39

ISSN : 2502-6496 (Print)

http://zona.pelantarpress.co.id

Dari AHP didapatkan hasil prioritas alternatif strategi adalah strategi pertama yaitu merumuskan dasar dan perangkat hukum beserta prosedur untuk menjaring partisipasi dari luar, seperti CSR dari perusahaan, terutama developer perumahan untuk membantu pengelolaan makam dan juga dari kegiatan ekonomi yang berlangsung di areal makam untuk membantu pendanaan TPU Tampa. Strategi kedua adalah memantapkan posisi RTH pemakaman TPU Tampan pada RTRW Kota Pekanbaru dengan mengacu pada RTRW Provinsi Riau dan mendorong pengesahan RTRW Kota Pekanbaru. Strategi ketiga adalah mengarahkan pengelolaan TPU Tampan, khususnya untuk meminimalkan resiko longsor, memaksimalkan pemanfaatan potensi SDA dan mengoptimalkan pengaturan petak makam dengan mengacu pada konsep pemakaman dalam bentuk RTH yang berhasil dan regulasi-regulasi yang ada. Dan strategi terakhir adalah pelibatan partisipasi masyarakat yang potensinya besar, karena persepsi masyarakat yang positif terhadap fungsi dan keberadaan dengan mensosialisasikan regulasi dan prosedur yang berlaku pada TPU Tampan dan memenuhi kebutuhan masyarakat terhadap RTH pemakaman TPU Tampan.

\section{KESIMPULAN}

Kesesuaian RTH pemakaman TPU Tampan dengan pedoman. TPU Tampan memenuhi 3 Dari 5 parameter yang diatur pada Perda Kota Pekanbaru no 3 tahun 2012, parameter tersebut adalah ukuran petak makam, tidak ada pengerasan dan pembagian makam beda agama. Untuk pedoman pada Permenpu no 5 tahun 2008, TPU Tampan memenuhi 3 dari 8 parameter yang ditetapkan, 3 paramater sesuai antara lain pembagian blok makam, pagar terluar dan persentase ruang hijau tanpa perkerasan beserta tingkat liputan vegetasi.

Persepsi yang bagus dari masyarakat terhadap peran RTH dan RTH pemakaman serta kesediaan untuk terlibat dalam perencanaan dan pengelolaan RTH pemakaman adalah hal yang positif untuk keberlangsungan RTH pemakaman.

Strategi ruang terbuka hijau pemakaman di Kota Pekanbaru hasil SWOT berada pada kuadran WO, lalu disusun prioritasnya dengan AHP adalah menjaring partisipasi dari luar, pengelolaan makam mengacu ke regulasi dan pemakaman dengan konsep RTH yang sudah berhasil, pemantapan posisi RTH pemakaman pada RTRW Kota Pekanbaru dan sosialisasi RTH pemakaman ke masyarakat.

\section{DAFTAR PUSTAKA}

Ardiansyah dan Oktapani, S. 2019. Analisis Penataan Ruang Terbuka Hijau Di Kota Pekanbaru. JISPO VOL. 9 No. 2 2019. Bandung.

Parlindungan, F. 2018. Strategi Pencapaian Ketersediaan dan Kebutuhan Ruang Terbuka Hijau di Kota Pekanbaru. Tesis. Program Magister Ilmu Lingkungan. Program Pasca Sarjana. Universitas Riau. Riau.

Peraturan Daerah Kota Pekanbaru Nomor 3 tahun 2012 Tentang Retribusi Pelayanan Pemakaman dan Pengabuan Mayat.

Peraturan Menteri Pekerjaan Umum Nomor: 05/PRT/M/2008 tahun 2014 Tentang Pedoman Penataan Ruang Terbuka Hijau di Kawasan Perkotaan.

Republik Indonesia. 2007. Undang-Undang Nomor 26 Tahun 2007 Tentang Penataan Ruang. Sekretariat Negara. Jakarta. 